\title{
Bundesvorstand transparent
}

\section{Sitzung des Regionalgruppenbeirates des djb am 25./26. April 2009 in Fulda}

Bei der Sitzung des Regionalgruppenbeirats des djb (RGB) am 25./26. April in Fulda wurde das Projekt „Bundesvorstand transparent - Teilnahme an BuVo-Sitzungen“ vorgestellt. Regionalgruppen und Landesverbände, denen kein Bundesvorstandsmitglied angehört, haben die Möglichkeit, eines ihrer Mitglieder zu einer BuVo-Sitzung zu entsenden. Die Vertreterinnen der Regionalgruppen und Landesverbände zogen bei der Vorsitzenden Richterin am Oberlandesgericht und Vizepräsidentin des djb Ramona Pisal Lose zur Teilnahme an den nächsten BuVo-Sitzungen. Aufgrund welchen Verfahrens das Mitglied in den einzelnen RG/LV ermittelt wird, obliegt der jeweiligen RG/LV.

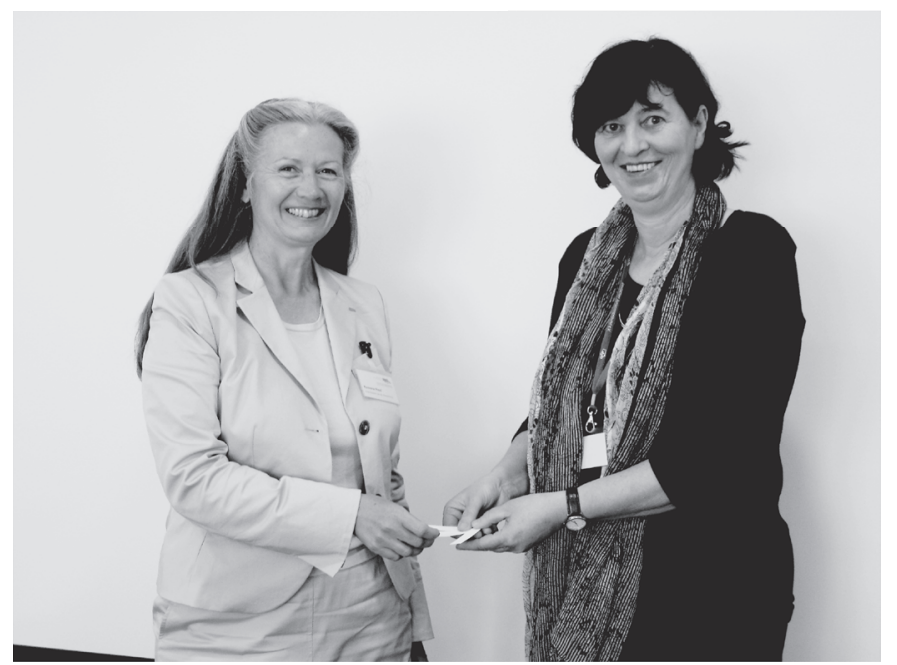

A Ramona Pisal, Vizepräsidentin des djb (Vors. Richterin am OLG, Brandenburg a.d.H.) und Birgit Kersten, Vorstandsmitglied im RGB (Rechtsanwältin und vereidigte Buchprüferin, Brake) verlosen die Teilnahme an den nächsten Bundesvorstandssitzungen in Berlin.

Die erste Regionalgruppe, die ein Mitglied in die BuVo-Sitzung am 4. Juli 2009 entsenden wird, ist Mainz. Steuerberaterin Sandra Pössel nahm das Los in Empfang.

Im Rahmen der RGB-Sitzung fanden turnusgemäß Vorstandswahlen statt. RAin Martina Bosch, RG Bonn, RAin, vBP, Birgit Kersten, RG Oldenburg, und Datenschutzbeauftragte Anke Schröder, RG Vorpommern, wurden einstimmig wiedergewählt. (BK)

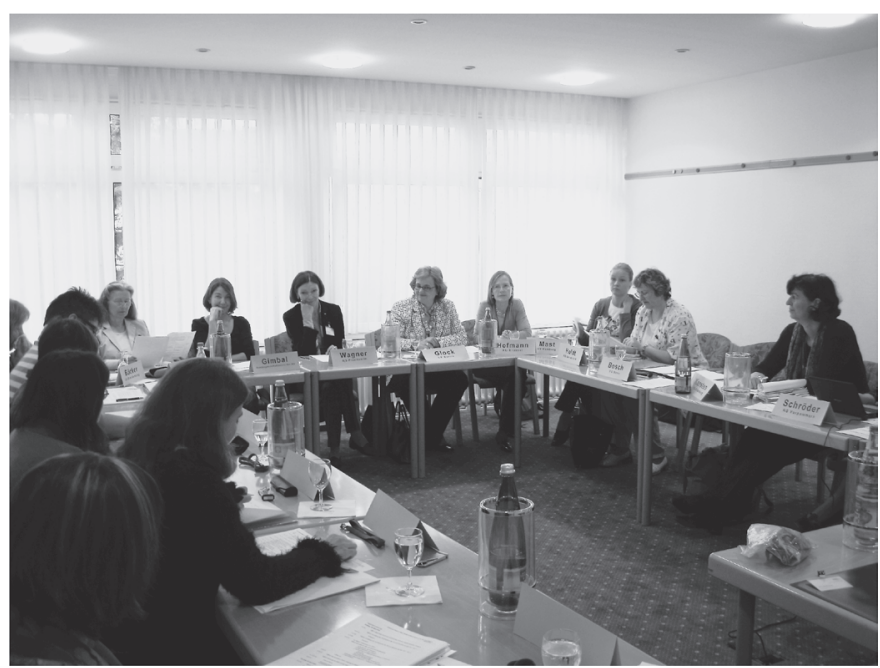

A Herzstück der Sitzungen des Regionalgruppenbeirats ist der Erfahrungsaustausch. Jede Gruppe teilt mit, welche Veranstaltungen im Vorjahr stattgefunden haben. Im Bild v.I.n.r.: djb-Präsidentin Jutta Wagner, die RGB-Delegierten Prof. (Asoc.) Dr. Jutta Glock (Vorsitzende LV Berlin), Margarete Hofmann (Vorsitzende RG Brüssel), Sigrun Mast (Vorstand LV Hamburg) und Susanne Holdt (RG Osnabrück, 2. Vorsitzende LV Niedersachsen).

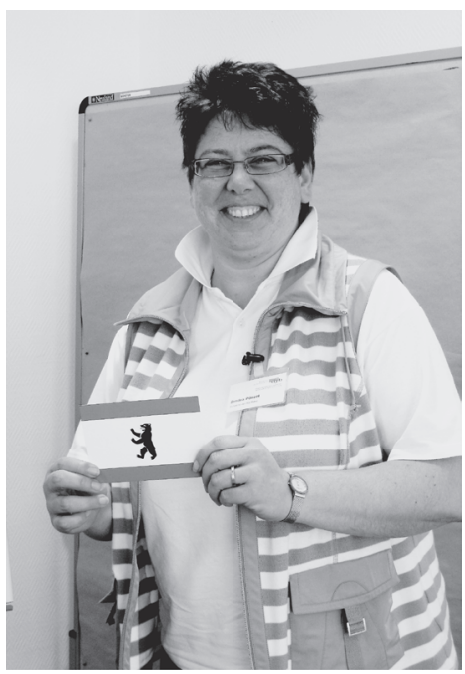

A Steuerberaterin Sandra Pössel, RG Mainz, mit dem Los der Aktion „Bundesvorstand transparent“. 